\title{
Vulvar Basal Cell Carcinoma
}

National Cancer Institute

\section{Source}

National Cancer Institute. Vulvar Basal Cell Carcinoma. NCI Thesaurus. Code C6381.

A slow growing, locally infiltrating carcinoma that arises from the vulva. It is characterized by the presence of malignant cells that resemble the basal cells that are present in the epidermis. 